\title{
The cadherin-catenin complex in nasopharyngeal carcinoma
}

\author{
H. Galera-Ruiz • M. J. Ríos · R. González-Cámpora • \\ M. de Miguel • M. I. Carmona • A. M. Moreno • \\ Hugo Galera-Davidson
}

Received: 29 July 2010/Accepted: 7 December 2010/Published online: 15 January 2011

(c) The Author(s) 2011. This article is published with open access at Springerlink.com

\begin{abstract}
Abnormal Wnt signaling and impaired cell-cell adhesion due to abnormal E-cadherin and $\beta$-catenin function have been implicated in many cancers, but have not been fully explored in nasopharyngeal carcinoma. The aim of this study was to analyze $\beta$-Catenin cellular location and E-cadherin expression levels in nasopharyngeal carcinoma. E-cadherin expression levels were also correlated with clinical data and underlying pathology. $\beta$-Catenin and E-cadherin expression were examined in 18 nasopharyngeal carcinoma and 7 non-tumoral inflammatory pharynx tissues using immunohistochemical methods. Patient clinical data were collected, and histological evaluation was performed by hematoxylin/eosin staining. $\beta$-catenin was detected in membrane and cytoplasm in all cases of nasopharyngeal carcinoma, regardless of histological type; in non-tumoral tissues, however, $\beta$-catenin was observed only in the membrane. As for E-cadherin expression levels, strong staining was observed in most non-tumoral tissues, but staining was only moderate in nasopharyngeal carcinoma tissues. E-cadherin expression was associated with $\beta$-catenin localization, study group, metastatic disease, and
\end{abstract}

\section{H. Galera-Ruiz}

Dpto. Cirugía Facultad de Medicina, Universidad de Sevilla, 41009 Sevilla, Spain

M. J. Ríos · R. González-Cámpora · M. de Miguel ·

M. I. Carmona · A. M. Moreno · H. Galera-Davidson ( $\square)$ Departamento de Citología e Histología Normal y Patológica, Facultad de Medicina Universidad de Sevilla, Avda. Sánchez-Pizjuán s/n, 41009 Sevilla, Spain

e-mail: hugo@us.es

H. Galera-Ruiz · R. González-Cámpora Hospital Universitario Virgen Macarena, 41009 Sevilla, Spain patient outcomes. Reduced levels of E-cadherin protein observed in nasopharyngeal carinoma may play an important role in invasion and metastasis. Cytoplasmic $\beta$-catenin in nasopharyngeal carcinoma may impair cellcell adhesion, promoting invasive behavior and a metastatic tumor phenotype.

Keywords Nasopharyngeal carcinoma $\beta \beta$-Catenin . E-cadherin · Wnt signaling

\section{Introduction}

Nasopharyngeal carcinoma (NPC) - a distinct subtype of head and neck squamous cell carcinoma with unique epidemiology, clinical characteristics, etiology, and histopathology [1] —is a rare malignant disease, although among southern Chinese a peak incidence rate of around 20-30 cases per 100,000 has been reported [2]. NPC has been classified by the World Health Organization (WHO) as both a keranitizing and a non-keranitizing carcinoma. The nonkeranitizing form (WHO II), which includes differentiated and undifferentiated non-keratinizing carcinoma, is more common in southern China, where it accounts for over 97\% of NPCs [3]. Previous reports have shown that environmental factors such as the intake of salted food, as well as Epstein-Barr virus (EBV) infection and genetic factors, are the major contributors to the etiology of NPC [4].

$\beta$-Catenin, originally identified on the basis of its association with cadherin adhesion molecules, is now widely recognized as an essential element in the wingless Wnt signaling cascade [5]. Wnt proteins bind to the receptors belonging to the Frizzled $(\mathrm{Fz})$ family. In the canonical pathway, $\beta$-catenin activates an intracellular cascade that involves the inhibition of glycogen synthase kinase $3 \beta$ 
(GSK 3 3 ) and the adenomatous polyposis coli (APC) protein, ultimately resulting in the abnormal stabilization of cytoplasmic $\beta$-catenin and its translocation to the nucleus. Nuclear $\beta$-catenin then interacts with various transcription factors to cause cellular proliferation and differentiation. Abnormal Wnt signaling has been implicated in a number of cancers including head and neck carcinoma, lung cancer, colorectal cancer, melanoma, and leukemia [6]. Although the role of the Wnt pathway in NPC has not been fully explored, there is abundant evidence that the aberrant Wnt signaling is involved in its development $[7,8]$.

Cytoplasmic $\beta$-catenin plays a major role in the normal cell by binding to the intracellular domain of E-cadherin to maintain cell-cell adhesion. The expression of E-cadherin has been found to be downregulated in many cancers [9-11] including NPC [12]. It has been suggested that E-cadherin downregulation may play a role in tumor progression and metastasis.

$\beta$-Catenin is significantly associated with invasion and metastasis of carcinomas of the head and neck, esophagus, stomach, colon, liver, lung, breast, female genitalia, prostate, bladder, and pancreas, as well as melanomas [11, 13-17]. Recently, several studies have pointed to the considerable involvement of $\beta$-catenin not only in malignant transformation but also in the regulation of physiological functions, and expression of this adhesion molecule in human nasopharyngeal carcinoma has been investigated $[18,19]$.

The present study sought to examine the possible role of molecular cell-cell adhesion mechanisms in the oncogenesis and/or cytodifferentiation of differentiated and undifferentiated non-keratinizing nasopharyngeal carcinoma. Expression of $\beta$-catenin and E-cadherin was determined by immunohistochemical analysis both in NPC patients and in non-tumor patients with inflammatory diseases of the pharynx.

\section{Materials and methods}

Patient samples and histological classification

Eighteen patients with NPC (11 men and 7 women, aged 44-78) were diagnosed at the Virgen Macarena University Hospital and the Infanta Luisa Hospital in Seville (Spain). The study was approved by the Ethical Committee and informed consent was obtained from all the participants in the study. NPC samples and non-tumoral inflammatory pharynx epithelium samples (control group; seven male patients aged 19-55) were routinely fixed in 10\% buffered formalin and embedded in paraffin. All the NPC patients were classified according to WHO criteria (1975): 11 $(61.1 \%)$ undifferentiated non-keratinizing carcinoma (type
3), $6(33.4 \%)$ differentiated non-keratinizing carcinoma (type 2), and 1 (5.5\%) keratinizing carcinoma (type 1).

All biopsy samples were dehydrated and embedded in paraffin. Histological evaluation was performed by two pathologists using hematoxylin/eosin staining. Patient clinical data and underlying pathologies are summarized in Table 1.

Inmunohistochemical staining

Paraffin-embedded tissue blocks from 18 NPC patients and 7 patients with non-tumoral pharyngeal inflammation were cut into $3 \mu \mathrm{m}$ sections and placed on APES pre-coated slides. Sections were deparaffinized in xylene and rehydrated in alcohol and water. Immunohistochemistry (IHC) was performed using the peroxidase-antiperoxidase technique after microwave antigen retrieval procedure. Antibodies for $\beta$-catenin and E-cadherin were purchased from ZYMED Laboratories (ZYMED Laboratories, San Francisco, CA, USA). Antibodies against $\beta$-catenin (1:200) and E-cadherin (1:100) were overlaid on NPC tissue array sections and incubated overnight at $4^{\circ} \mathrm{C}$. Secondary antibody incubation was performed at room temperature for $30 \mathrm{~min}$. Two pathologists independently scored the results of immunohistochemical staining, and any discrepant scores were reexamined to arrive at a consensus score.

For $\beta$-catenin, +++ indicates posivite staining in membrane, cytoplasm and nucleus; ++ , positive staining in membrane and cytoplasm; + , positive staining in membrane. For E-cadherin, + indicates $0-33 \%$ staining cells, i.e. low staining;,$++ 33-66 \%$ staining cells, i.e. moderate staining;,$+++ 66-100 \%$ staining cells, i.e. strong staining. Colorectal cancer and demoid tumor were used as positive control and negative controls were obtained by replacing primary antibodies by PBS.

Statistical analysis

Results, expressed as mean \pm SEM, were analyzed using Student's test. Correlations between antigen immunoreactivity, histopathological findings and clinical data were evaluated by the Chi-square test. Differences were regarded as significant if $p<0.05$.

\section{Results}

Clinical data and histological classification

Patient clinical data and underlying pathologies are summarized in Table 1 and Fig. 1. All patients received radiotherapy and chemotherapy (RT $+\mathrm{QT})$. No correlation was found between clinical data (age, sex, recurrence, 
Table 1 Clinical data and histological classification

\begin{tabular}{|c|c|c|c|c|c|c|c|}
\hline & Age (years) & $\operatorname{Sex}^{a}(f / m)$ & Histologic classification & Metastasis & Stage & Treatment & Evolution \\
\hline 1 & 47 & $\mathrm{~m}$ & type 2 NPC & Yes & IV & $\mathrm{QT}+\mathrm{RT}$ & Recurrence \\
\hline 2 & 71 & $\mathrm{~m}$ & type 2 NPC & No & II & $\mathrm{QT}+\mathrm{RT}$ & Dead \\
\hline 3 & 54 & $\mathrm{~m}$ & type 2 NPC & Yes & II & $\mathrm{QT}+\mathrm{RT}$ & Recurrence \\
\hline 4 & 56 & $\mathrm{~m}$ & type 2 NPC & No & II & $\mathrm{QT}+\mathrm{RT}$ & Disease-free \\
\hline 5 & 64 & f & type 3 NPC & Yes & III & $\mathrm{QT}+\mathrm{RT}$ & Dead \\
\hline 6 & 64 & $\mathrm{f}$ & type $1 \mathrm{NPC}$ & Yes & II & $\mathrm{QT}+\mathrm{RT}$ & Recurrence \\
\hline 7 & 51 & f & type 2 NPC & Yes & II & $\mathrm{QT}+\mathrm{RT}$ & Dead \\
\hline 8 & 73 & f & type 3 NPC & No & I & $\mathrm{QT}+\mathrm{RT}$ & Dead \\
\hline 9 & 74 & $\mathrm{~m}$ & type 3 NPC & Yes & II & $\mathrm{QT}+\mathrm{RT}$ & Disease-free \\
\hline 10 & 46 & $\mathrm{~m}$ & type 3 NPC & Yes & III & $\mathrm{QT}+\mathrm{RT}$ & Dead \\
\hline 11 & 46 & $\mathrm{~m}$ & type 3 NPC & Yes & II & $\mathrm{QT}+\mathrm{RT}$ & Dead \\
\hline 12 & 60 & $\mathrm{~m}$ & type 3 NPC & Yes & II & $\mathrm{QT}+\mathrm{RT}$ & Recurrence \\
\hline 13 & 44 & $\mathrm{~m}$ & type 3 NPC & No & III & $\mathrm{QT}+\mathrm{RT}$ & Disease-free \\
\hline 14 & 78 & f & type 2 NPC & No & II & $\mathrm{QT}+\mathrm{RT}$ & Disease-free \\
\hline 15 & 60 & f & type 3 NPC & Yes & III & $\mathrm{QT}+\mathrm{RT}$ & Disease-free \\
\hline 16 & 70 & f & type 3 NPC & Yes & III & $\mathrm{QT}+\mathrm{RT}$ & Disease-free \\
\hline 17 & 55 & $\mathrm{~m}$ & type 3 NPC & Yes & III & $\mathrm{QT}+\mathrm{RT}$ & Dead \\
\hline 18 & 63 & $\mathrm{~m}$ & type 3 NPC & Yes & IV & $\mathrm{QT}+\mathrm{RT}$ & Dead \\
\hline 18 & 45 & $\mathrm{~m}$ & NT inflammatory of pharynx & No & & & Disease-free \\
\hline 20 & 29 & $\mathrm{~m}$ & NT inflammatory of pharynx & No & & & Disease-free \\
\hline 21 & 53 & $\mathrm{~m}$ & NT inflammatory of pharynx & No & & & Disease-free \\
\hline 22 & 21 & $\mathrm{~m}$ & NT inflammatory of pharynx & No & & & Disease-free \\
\hline 23 & 36 & $\mathrm{~m}$ & NT inflammatory of pharynx & No & & & Disease-free \\
\hline 24 & 55 & $\mathrm{~m}$ & NT inflammatory of pharynx & No & & & Disease-free \\
\hline 25 & 19 & $\mathrm{~m}$ & NT inflammatory of pharynx & No & & & Disease-free \\
\hline
\end{tabular}

${ }^{\mathrm{a}}(f$ female, $m$ male $)$

$N T$ inflammation of pharynx ${ }^{\prime}$ Non-tumoral inflammation of pharynx, $Q T+R T$ chemotherapy plus radiotherapy
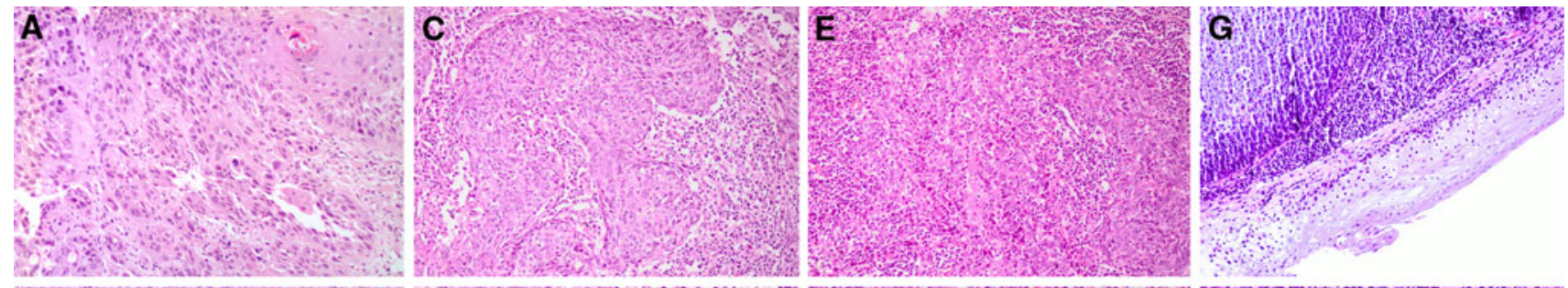
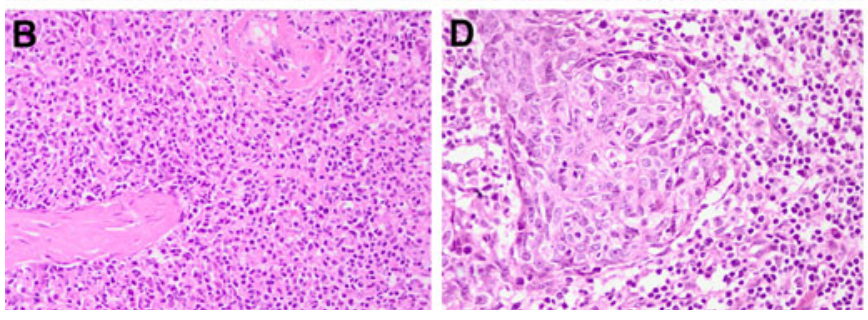

Fig. 1 Hematoxylin/eosin staining. a $(\times 20)$ and $\mathbf{b}(\times 40)$, keratinizing carcinoma (type 1) with squamous differentiation, showing intercellular bridges, keratin deposits and pearly appearance. $\mathbf{c}(\times 20)$ and $\mathbf{d}(\times 40)$, non-keratinizing squamous carcinoma (type 2$)$ : varied degree of cell differentiation but no keratin production. $\mathbf{e}(\times 20)$ and
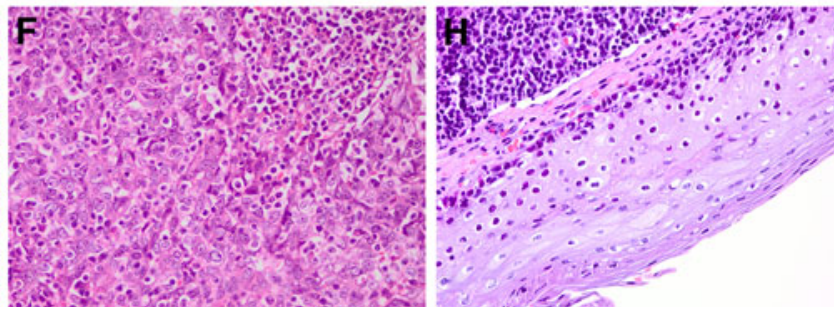

f $(\times 40)$, undifferentiated non-keratinizing carcinoma (type 3$)$ : lymphoepithelial proliferation, lymphoid cells breaking the tumor into nests, syncytial pattern, and cells with round nuclei and prominent nucleoli. $\mathbf{g}(\times 20)$ and $\mathbf{h}(\times 40)$, non-tumoral inflammation of the pharynx 
metastasis and mortality), histological type or mitotic numbers.

Immunohistochemical analysis of $\beta$-catenin and E-cadherin

Protein expression was analyzed by immunohistochemical staining for anti- $\beta$-catenin and anti-E-cadherin antibodies in NPC and non-tumoral tissues. The seven non-tumoral tissues showed equally strong membranous expression of $\beta$-catenin, which was detected in both cytoplasm and membrane in only $35 \%$ of cases. In contrast, $\beta$-catenin expression was detected in the membrane and cytoplasm of all NPC cases (Fig. 2). No significant differences in expression were recorded as a function of $\beta$-catenin localization, tumor staging, metastasis, or patient outcomes.

With regard to the levels of E-cadherin expression, strong staining was observed in $73 \%$ of non-tumoral tissues, and moderate expression in $27 \%$ of cases. By contrast, moderate staining was observed in $90.5 \%$ of NPC tissues, strong staining in $4.75 \%$ and low staining in $4.75 \%$ of cases. Staining was moderate in all type 1 and type 3 NPC tissues, and in most (80\%) type 2 NPC tissues (Figs. 3, 4).

Whilst no correlation was noted between $\beta$-catenin expression and clinical data (age, sex, evolution, and metastasis), E-cadherin expression was associated with $\beta$-catenin localization $(p=0.006)$ : elevated levels of E-cadherin protein expression were observed when $\beta$-catenin was localized in membrane, whilst moderate levels were recorded when $\beta$-catenin was not only localized in membrane but also in cytoplasm. A significant correlation was also found between E-cadherin expression and study group ( $p=$ 0.003): E-cadherin protein levels were higher in the control group than in the NPC groups. E-cadherin protein levels were also associated with metastasis $(p=0.002)$ and patient outcomes $(p=0.013)$ : NPC patients with poor prognosis displayed lower levels of E-cadherin expression than those displaying neither recurrence nor metastasis.

\section{Discussion}

NPC tumor cells are very likely to invade surrounding tissue or metastasize to cervical lymph nodes in the early stages of tumor development [20]. However, the major relevant mechanism remains unknown. Many factors may be involved in local invasion and distant metastasis, including cell-cell adhesion molecules, matrix metalloproteinase family and cytokines, which can alter the mobility and distribution of tumoral cells [21, 22].

$\beta$-Catenin contributes both to cell-cell adhesion and to the Wnt signaling pathway [23, 24]. The cadherin-catenin complex is a group of membrane proteins that is important in cell-cell adhesion, tumor suppression, cell differentiation and cell migration. Some reports have suggested that downregulated expression of $\beta$-catenin might play a role in early and late tumor invasion and metastasis [25, 26]. Downregulation of $\beta$-catenin has been found to be closely related to advanced clinical disease and short survival in NPC patients [12]. The present study, however, noted no alteration in $\beta$-catenin protein expression, and no
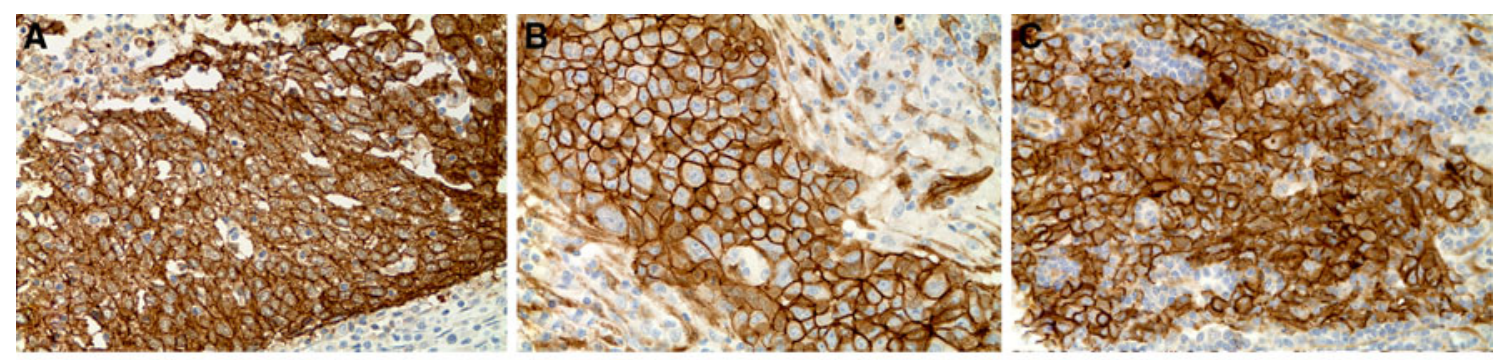
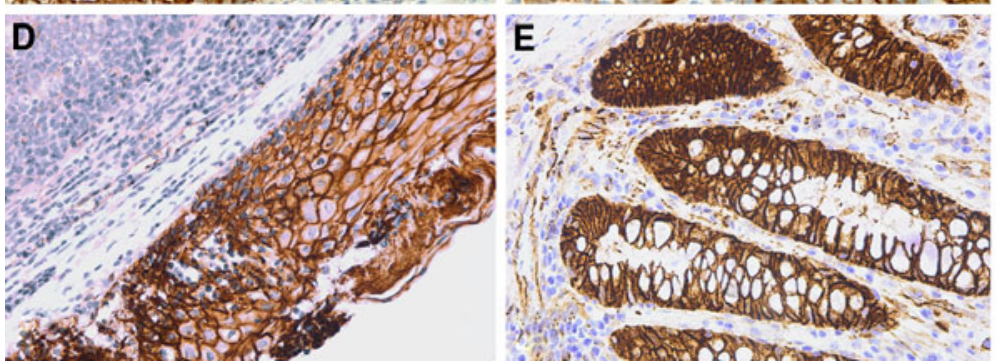

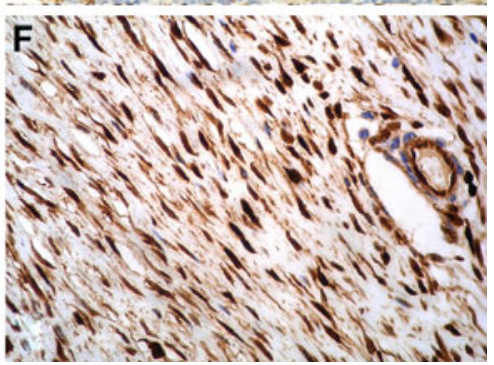

carcinoma (type 2). c $(\times 40)$, undifferentiated non-keratinizing carcinoma (type 3$)$. d $(\times 40)$, non-tumoral pharyngeal inflammation. Positive controls for nuclear $\beta$-catenin: e $(\times 40)$, colorectal carcinoma. f $(\times 40)$, desmoid tumor 
Fig. 3 Immunohistochemical staining for E-cadherin expression in 18 nasopharyngeal carcinoma tissues. a $(\times 40)$, keratinizing carcinoma. b $(\times 40)$, differentiated non-keratinizing carcinoma (type 2$)$. c $(\times 40)$, undifferentiated nonkeratinizing carcinoma (type 3). a-c Moderate staining for E-cadherin protein, $\mathbf{d}(\times 40)$ non-tumoral pharyngeal inflammation; strong staining for E-cadherin protein
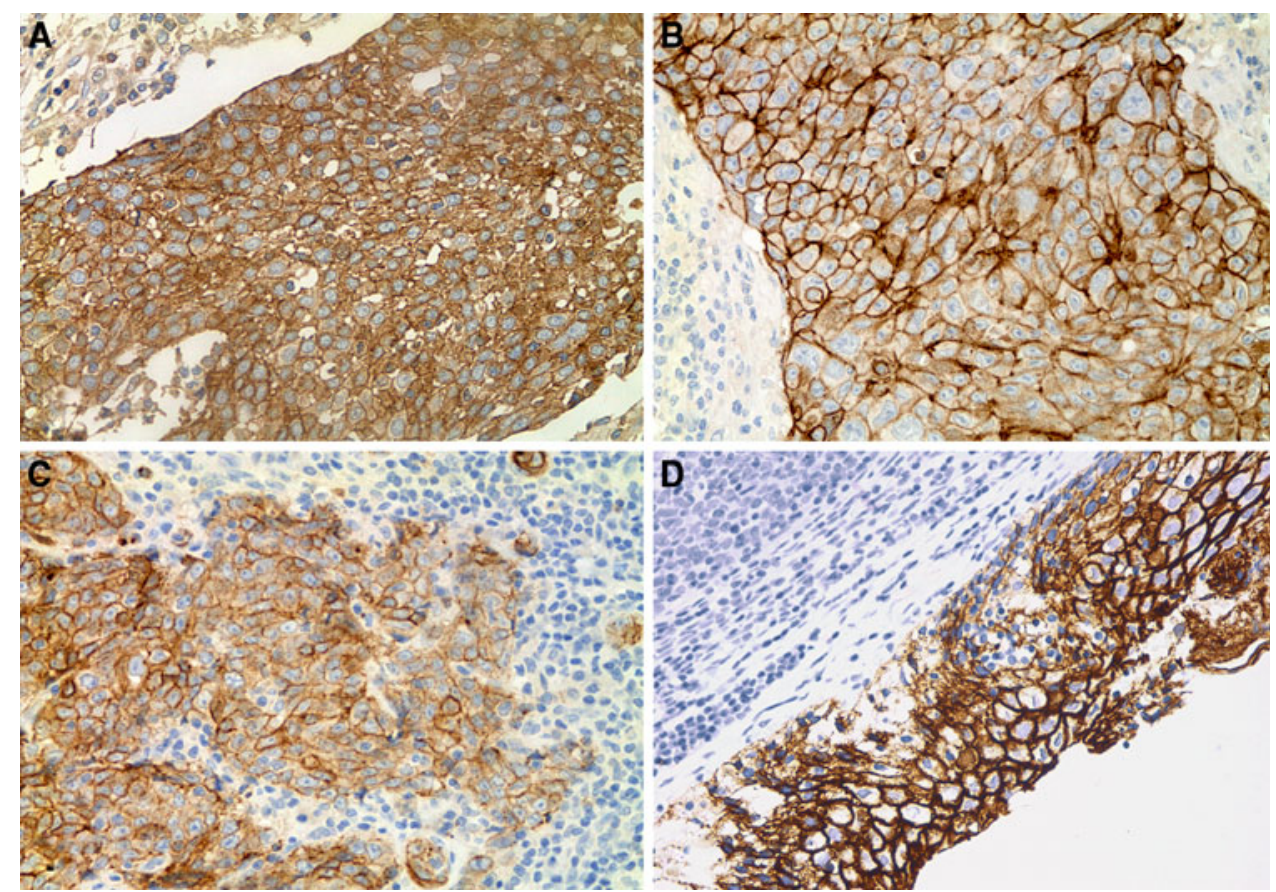

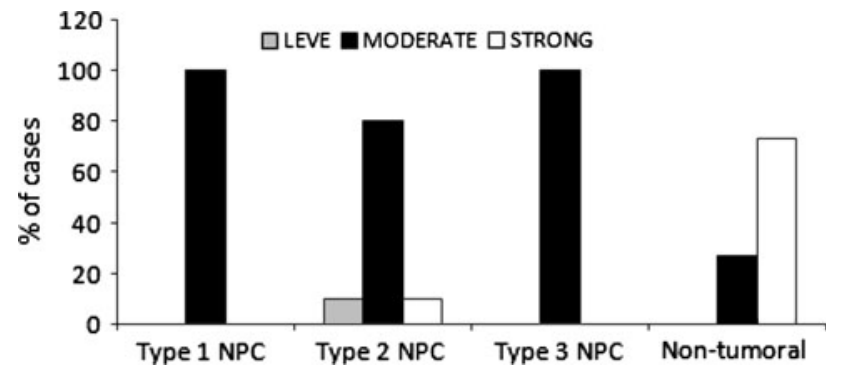

Fig. 4 E-cadherin protein expression in nasopharyngeal carcinoma tissues and non-tumoral inflammatory pharynx tissues. Data are expressed as mean of cases per study group (\%)

correlation between its expression and NPC patient outcomes. These results suggest that $\beta$-catenin may not in itself be a major factor for NPC tumor cell invasion and metastasis. Here, $\beta$-catenin protein levels were evaluated using inmunohistochemical staining, a semi-quantitative technique enabling assessment of proteins in paraffinembedded tissues. Further research will evaluate $\beta$-catenin expression levels using the western blot technique, with a view to measuring possible alterations in $\beta$-catenin protein levels in fresh tissue.

$\beta$-Catenin is also involved in the Wnt canonical pathway as a transcriptional activator $[23,24]$. The inhibition of glycogen synthase kinase (GSK-3 $\beta$ ) and the adenomatous polyposis coli (APC) protein ultimately results in the stabilization and nuclear translocation of cytoplastic $\beta$-catenin. Finally, nuclear $\beta$-catenin interacts with various transcription factors to cause proliferation and differentiation. However, further research is required to link altered $\beta$-catenin levels and development of NPC. Here, $\beta$-catenin was detected in membrane and cytoplasm, but not in the nucleus. Although Zheng et al. [12] found nuclear $\beta$-catenin in five cases of undifferentiated NPC, other authors have failed to detect nuclear $\beta$-catenin. Li et al. [27] observed increased membrane $\beta$-catenin but no nuclear $\beta$-catenin in 42 NPC patients; by contrast, Zhi et al. [28] found no nuclear or cytoplasmic $\beta$-catenin in any NPC tissues studied. In the present study, failure to detect nuclear $\beta$-catenin suggests that the canonical Wnt pathway may be inactivated in this type of cancer. However, this cannot be categorically confirmed, since stabilized $\beta$-catenin was detected in cytoplasm. Further research will be necessary to determine whether the Wnt pathway is activated by overexpression of its receptors or silencing of its suppressors, and also to investigate the possible activation of the non-canonical Wnt pathway that includes signaling through calcium flux, JNK and heterotrimeric G proteins.

E-cadherin is essential for normal cell function, and downregulated in processes such as wound healing, allowing epithelial cells to move and cover denuded tissue [29]. E-cadherin, localized to the zonula adherens, complexes with catenins $\beta$ and $\gamma ; \beta$ - and $\gamma$-catenins in turn bind to $\alpha$-catenin which attaches to the actin filaments in the cell cytoskeleton [30]. E-cadherin is thought to act as a tumor suppressor, since it suppresses invasion and metastasis [31]. Low expression of E-cadherin has been shown to predict poor outcome in oral cavity and laryngeal carcinomas [32, 33]. In this study, moderate E-cadherin expression was detected in all type 1 and type 3 NPC tissues and in almost all type 2 tissues. By contrast, strong 
E-cadherin expression was detected in non-tumoral tissues, so that downregulation of E-cadherin expression in NPC tissues may indicate a greater capacity for invasion and metastasis. Indeed, a positive correlation was observed between E-cadherin expression levels, the presence of lymph node metastasis in NPC tissues and patient outcomes. In this respect, several studies have shown that diminished E-cadherin expression is a good predictor of concurrent lymph node metastasis in laryngeal carcinoma, and head and neck squamous cell cancer [34-36]. Zhi et al. [28] noted a correlation between reduced E-cadherin expression and NPC lymph node metastasis. In some cancer cells, aberrant gene promoter methylation of E-cadherin may be responsible for the decreased expression of E-cadherin [34, 35]; future research will therefore focus on possible epigenetic changes due to promoter hypermethylation in NPC tissues.

Finally, a correlation was observed between E-cadherin protein levels and $\beta$-catenin localization, low levels being associated with $\beta$-catenin in cytoplasm. Other studies of head and neck squamous cell carcinomas report loss of membranous E-cadherin and $\beta$-catenin expression and increased cytoplasmic expression, irrespective of the primary carcinoma or nodal carcinoma involved [37]. Impairment of cell-cell adhesion is an essential step in the progression from localized malignancy to stromal and vascular invasion and metastatic disease. This impairment is achieved through a variety of mechanisms involving the cadherin/catenin complex [38].

The results obtained here suggest an enhancement of the potential ability of cancer cells to disperse, a preliminary step in local invasion. A better knowledge of the regulation of the cadherin-catenin system is required for the prevention or treatment of nasopharyngeal carcinoma.

In conclusion, reduced levels of E-cadherin protein in NPC may play an important role in invasion and metastasis. Cytoplasmic $\beta$-catenin in NPC leads to impaired cell-cell adhesion, promoting invasive behavior and a metastatic tumor phenotype. Further research is required to clarify the involvement of $\beta$-catenin in the mechanism associated with malignant transformation in nasopharyngeal tissues.

Conflict of interest Authors have no conflict of interest.

Open Access This article is distributed under the terms of the Creative Commons Attribution Noncommercial License which permits any noncommercial use, distribution, and reproduction in any medium, provided the original author(s) and source are credited.

\section{References}

1. Vokes EE, Liebowitz DN, Weichselbaum RR (1997) Nasopahryngeal carcinoma. Lancet 350:1087-1091
2. Yu MC, Yuan JM (2002) Epidemiology of nasopharyngeal carcinoma. Semin Cancer Biol 12:421-429

3. Marks JE, Phillips JL, Menck HR (1998) The National Cancer Data Base report on the relationship of race and national origin to the histology of nasopharyngeal carcinoma. Cancer 83:582-588

4. Lo KW, To KF, Huang DP (2004) Focus on nasopharyngeal carcinoma. Cancer Cell 5:423-428

5. Mc Crea PD, Gumbiner BM (1991) Purification of a 92-kDa cytoplasmic protein tightly associated with the cell-cell adhesion molecule E-cadherin (uvomorulin). J Biol Chem 266:1359-1361

6. Mazieres J, He B, You L, Xu Z, Jablons D (2005) Wnt signalling in lung cancer. Cancer Lett 222:1-10

7. Morrison J, Gulley M, Pathmanathan R, Raab-Traub N (2004) Differential signaling pathways are activated in the Epstein-Barr virus-associated malignancies nasopharyngeal carcinoma and Hodgkin lymphoma. Cancer Res 64:5251-5260

8. Zeng ZY, Zhou YH, Zhang WL et al (2007) Gene expression profiling of nasopharyngeal carcinoma reveals abnormally regulated Wnt signalling pathway. Human Pathol 38:120-133

9. Hoteiya T, Hayashi E, Satomura K et al (1999) Expression of E-cadherin in oral cancer cell lines and its relationship to invasiveness in SCID mice in vivo. J Oral Pathol Med 28:107-111

10. Garcia del Muro X, Torregrosa A, Munoz J et al (2000) Prognostic value of the expression of E-cadherin and beta-cateninin bladder cancer. Eur J Cancer 36:357-362

11. Kim HC, Kim HJ, Kim JC (2002) Reduced E-cadherin expression as a cause of distinctive signet-ring cell variant in colorectal carcinoma. J Korean Med Sci 17:23-28

12. Zheng Z, Pan J, Chu B, Wong YC et al (1999) Downregulation and abnormal expression of E-cadherin and beta-catenin in nasopharyngeal carcinoma: close association with advanced disease stage and lymph node metastasis. Hum Pathol 130:458-466

13. Rubinfeld B, Robbins P, El-Gamil M, Albert I, Porfiri E, Polakis P (1997) Stabilization of beta-catenin by genetic defects in melanoma cell lines. Science 275:1790-1792

14. Osterheld MC, Bian YS, Bosman FT, Benhattar J, Fontolliet C (2002) Beta-catenin expression and its association with prognostic factors in adenocarcinoma developed in Barrett esophagus. Am J Clin Pathol 117:451-456

15. Sugio K, Kase S, Sakada T, Yamazaki K, Yamaguchi M, Ondo K et al (2002) Micrometastasis in the bone marrow of patients with lung cancer associated with a reduced expression of E-cadherin and beta-catenin: risk assessment by immunohistochemistry. Surgery 131:226-231

16. Perl AK, Wilgenbus P, Dahl U, Semb H, Christofori G (1998) A causal role for E-cadherin in the transition from adenoma to carcinoma. Nature 12:190-193

17. Montgomery E, Torbenson MS, Kaushal M, Fisher C, Abraham SC (2002) Beta-catenin immunohistochemistry separates mesenteric fibromatosis from gastrointestinal stromal tumor and sclerosing mesenteritis. Am J Surg Pathol 26:1296-1301

18. Chou Josephine, Lin Yun-Ching, Kim Jae, You Liang, Zhidong Xu, Biao He, Jablons David M (2008) Nasopharyngeal carcinoma-review of the molecular mechanism of tumorogénesis. Head Neck 230(7):946-963

19. Jou T, Stewart D, Stappert J, Nelson W, Marrs J (1995) Genetic and biochemical dissection of protein linkages in the cadherincatenin complex. Proc Natl Acad Sci USA 92:5067-5071

20. Fandi A, Altun M, Azli N et al (1994) Nasopharyngeal cancer: epidemiology, staging, and treatment. Semin Oncol 21:382-397

21. Horikawa T, Yoshizaki T, Shen TS et al (2000) Association of latent membrane protein 1 and matrix metalloproteinase 9 with metastasis in nasopharyngeal carcinoma. Cancer 89:715-723

22. Lim SC, Lee MS (2002) Significance of E-cadherin/beta-catenin complex and cyclin D1 in breast cancer. Oncol Rep 9:915-928 
23. Clements WM, Wang J, Sarnaik A et al (2002) Beta-catenin mutation is a frequent cause of Wnt pathway activation in gastric cancer. Cancer Res 62:3503-3506

24. Gumbiner BM (1997) Carcinogenesis: a balance between betactenin and APC. Curr Biol 7:443-446

25. Joo YE, Rew JS, Choi SK et al (2002) Expression of E-cadherin and catenins in early gastric cancer. J Clin Gastroenterol $35: 35-42$

26. Kallakury BV, Sheehan CE, Winn-Deen E et al (2001) Decreased expression of catenin (alpha and beta), p120 CTN, and E-cadherin cell adhesion proteins and E-cadherin gene promoter methylation in prostatic adenocarcinomas. Cancer 92:2786-2795

27. Li Z, Lin SX, Liang YJ (2003) Influence of E-cadherin promoter methylation and mutation of beta-catenin on invasion and metastasis of nasopharyngeal carcinoma cells. Zhonghua Zhong Liu Za Zhi 25(3):238-242

28. Zhi Li, Ren Yi, Su-xia Lin, Ying-jie Liang, Hui-Zhen Liang (2004) Association of E-cadherin and $\beta$-catenin with metastasis in nasopharyngeal carcinoma. Chin Med J 117(8):1232-1239

29. Dogan A, Wang ZD, Spencer J (1995) E-cadherin expression in intestinal epithelium. J Clin Pathol 48:143-146

30. Hajra KM, Fearon ER (2002) Cadherin and catenin alterations in human cancer. Genes Chromosomes Cancer 34:255-268

31. Takeichi M (1993) Cadherins in cancer: implications for invasion and metastasis. Curr Opin Cell Biol 5:806-811
32. Chow V, Yuen APW, Lam KY et al (2001) A comparative study of the clinicopathological significance of E-cadherin and catenins $(\alpha, \beta, \gamma)$ expression in the surgical management of oral tongue carcinoma. J Cancer Res Clin Oncol 127:59-63

33. Mattijssen V, Peters HM, Schalkwijk L et al (1993) E-cadherin expression in head and neck squamous-cell carcinoma is associated with clinical outcome. Int J Cancer 55:580-585

34. Franchi A, Gallo O, Boddi V et al (1996) Prediction of occult neck metastases in laryngeal carcinoma: role of proliferating cell nuclear antigen, MIB-1, and E-cadherin immunohistochemical determination. Clin Cancer Res 2:1801-1808

35. Rodrigo JP, Dominguez F, Alvarez C et al (2002) Expression of E-cadherin in squamous cell carcinomas of the supraglottic larynx with correlations to clinicopathological features. Eur J Cancer 38:1059-1064

36. Takes RP, Baatenburg de Jong RJ, Alles MJRC et al (2002) Markers for nodal metastasis in head and neck squamous cell cancer. Arch Otolaryngol Head Neck Surg 128:512-518

37. Andrews NA, Jones AS, Helliwell TR et al (1997) Expression of the E-cadherin-catenin cell adhesion complex in primary squamous cell carcinomas of the head and neck and their nodal metastases. Br J Cancer 75:1474-1480

38. Beavon IRG (2000) The E-cadherin-catenin complex in tumour metastasis: structure, function and regulation. Eur J Cancer 36: $1607-1620$ 